- Review Article

\title{
An Overview and Update of Chronic Myeloid Leukemia for Primary Care Physicians
}

\author{
Austin Granatowicz', Caroline I. Piatek ${ }^{2}$, Elizabeth Moschiano ${ }^{3}$, Ihab El-Hemaidi ${ }^{4}$, Joel D. Armitage ${ }^{5}$, \\ Mojtaba Akhtari ${ }^{2, *}$ \\ 'College of Medicine, University of Nebraska Medical Center, Omaha, USA \\ ${ }^{2}$ Jane Anne Nohl Division of Hematology and Center for the Study of Blood Diseases, University of Southern California (USC)/Norris Cancer Center, \\ USC University Hospital, Los Angeles, USA \\ ${ }^{3}$ Department of Pathology, Veterans Affairs West Los Angeles Medical Center, Los Angeles, USA \\ ${ }^{4}$ Consultant Adult Hematology/BMT, Princess Noorah Oncology Center, Jeddah, Kingdom of Saudi Arabia \\ ${ }^{5}$ Division of General Internal Medicine, Department of Internal Medicine, University of Nebraska Medical Center, Omaha, USA
}

Chronic myeloid leukemia (CML) accounts for approximately $15 \%$ of adult leukemias. Forty percent of patients with CML are asymptomatic, in whom the disease is detected solely based on laboratory abnormalities. Since the introduction of tyrosine kinase inhibitor therapy in 2001, CML has become a chronic disease for the majority of patients. Primary care physicians may be the first to recognize a new diagnosis of CML. In patients with known CML, the primary care physician may be the first to detect disease progression or adverse effects to therapy. This article provides an overview of the clinical presentation, diagnostic approach, and treatment considerations of CML.

Keywords: Leukemia, Myelogenous, Chronic, BCR-ABL Positive; Primary Health Care 


\section{INTRODUCTION}

Chronic myeloid leukemia (CML) accounts for approximately $15 \%$ of adult leukemias, with an estimated 6,660 new cases of CML diagnosed in the United States in 2015. ${ }^{1)}$ Although the median age of diagnosis is 67 years, CML may present at any age. ${ }^{2)}$ The advent of tyrosine kinase inhibitor (TKI) therapy has transformed CML from a fatal disease into a chronic disease for the majority of patients. Prior to 1983, the 8-year survival of CML was less than $15 \%$. The 8-year survival improved from $42 \%$ to $65 \%$ from 1983 to 2000 with the use of interferon- $\alpha$-based therapy and allogeneic hematopoietic stem cell transplant (HSCT) therapy. With the introduction of TKI therapy in 2001, the 8 -year survival is now $87 \%$ and continues to improve with the use of second- and third-generation TKI therapy. ${ }^{3)}$ Given the dramatic decrease in the number of deaths in CML patients and the stable incidence, the prevalence of CML continues to increase. The estimated prevalence of CML in the United States was approximately 70,000 in 2010 and is expected to increase to approximately 112,000 in $2020 .^{4)}$

\section{PATHOGENESIS}

CML is a clonal myeloproliferative disorder characterized by the presence of a balanced genetic translocation of chromosomes 22 and 9, termed the Philadelphia (Ph) chromosome (Figure 1). The resulting breakpoint cluster region-Abelson murine leukemia (BCR-ABL) fusion oncogene is translated into the BCR-ABL oncoprotein. ${ }^{5)} \mathrm{BCR}-\mathrm{ABL}$ is a constitutively active tyrosine kinase that activates a number of signal-transduction pathways that affect the growth and survival of hematopoietic cells. ${ }^{6)}$

\section{CLINICAL MANIFESTATIONS AND STAGING}

CML is classified into three different phases: chronic, accelerated, and blast (Table 1). ${ }^{7-9)}$ The natural history of CML is a chronic phase for three to five years followed by rapid progression to the fatal blast phase. In two-thirds of patients, the blast phase

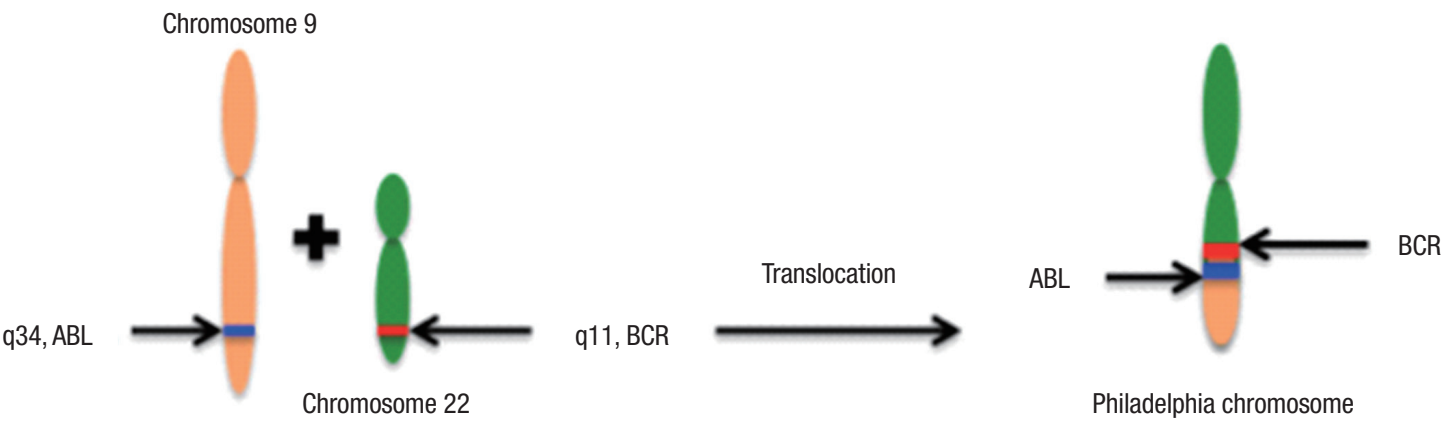

Figure 1. The Philadelphia chromosome. ABL, Abelson murine leukemia; BCR, breakpoint cluster region.

Table 1. Stages of chronic myeloid leukemia

\begin{tabular}{|c|c|}
\hline Phase & Criteria \\
\hline Chronic phase & None of the criteria for accelerated or blast phase are present \\
\hline \multicolumn{2}{|l|}{ Accelerated phase } \\
\hline $\begin{array}{l}\text { MD Anderson Cancer Center and European LeukemiaNet criteria* } \\
\text { (most commonly used in clinical trials) }\end{array}$ & $\begin{array}{l}\text { Blasts } \geq 15 \% \text { and }<30 \% \text { in the peripheral blood or bone marrow } \\
\text { Combined blasts and promyelocytes } \geq 30 \% \text { in the peripheral blood or bone marrow } \\
\text { Basophilia } \geq 20 \% \text { in the peripheral blood } \\
\text { Platelets } \leq 100 \times 10^{9} / \mathrm{L} \text { unrelated to therapy } \\
\text { Cytogenetic clonal evolution }\end{array}$ \\
\hline WHO criteria $^{\dagger}$ & $\begin{array}{l}\text { Blasts } 10 \% \text { to } 19 \% \text { in the peripheral blood or bone marrow } \\
\text { Basophilia } \geq 20 \% \text { in the peripheral blood } \\
\text { Persistent thrombocytopenia }\left(<100 \times 10^{9} / \mathrm{L}\right) \text { unrelated to therapy } \\
\text { Persistent thrombocytosis }\left(>1,000 \times 10^{\%} / \mathrm{L}\right) \text { unresponsive to therapy } \\
\text { Increasing spleen size and white blood cell count unresponsive to therapy } \\
\text { Cytogenetic clonal evolution }\end{array}$ \\
\hline \multicolumn{2}{|l|}{ Blast phase } \\
\hline MD Anderson Cancer Center and European LeukemiaNet criteria & $\begin{array}{l}\text { Blasts } \geq 30 \% \text { in the peripheral blood or bone marrow } \\
\text { Extramedullary blast proliferation, apart from the spleen }\end{array}$ \\
\hline WHO criteria & $\begin{array}{l}\text { Blasts } \geq 20 \% \text { in the peripheral blood or bone marrow } \\
\text { Extramedullary blast proliferation, apart from the spleen } \\
\text { Large foci or clusters of blasts in the bone marrow biopsy }\end{array}$ \\
\hline
\end{tabular}


is proceeded by an accelerated phase.

Approximately $85 \%$ of patients with CML are diagnosed in the chronic phase ${ }^{10)}$ Forty percent of patients with chronic phase CML are asymptomatic with the diagnosis made solely based on an abnormal blood count. ${ }^{6}$ Among the patients who have symptoms, complaints are usually related to anemia and splenomegaly; these include fatigue, weight loss, anorexia, early satiety, and left upper quadrant pain or fullness. Other less common symptoms include thrombosis or bleeding from thrombocytopenia or platelet dysfunction. Splenomegaly is the most common finding on physical exam and is present in over half of patients. ${ }^{11)}$

\section{DIAGNOSIS}

Unexplained leukocytosis with left shift (immature myeloid cells including myelocytes, promyelocytes or blasts), basophil-

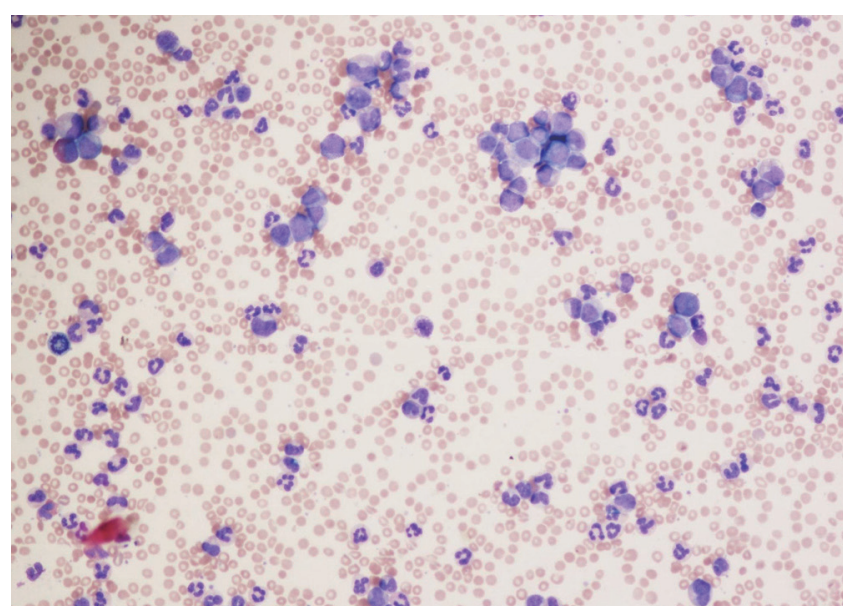

Figure 2. Peripheral blood of chronic phase chronic myeloid leukemia showing leukocytosis with circulating immature myeloid cells (Wright-Giemsa stain, $\times 4$ ).



Figure 3. Bone marrow aspirate of chronic phase chronic myeloid leukemia showing a spectrum of immature myeloid cells including blasts and promyelocytes (Wright-Giemsa stain, $\times 20$ ). ia, and splenomegaly are suggestive of CML (Figure 2). The differential diagnosis includes leukemoid reaction (due to infection or inflammation), $\mathrm{Ph}$ negative myeloproliferative disorder, chronic myelomonocytic leukemia, and proliferative myelodysplastic syndrome. On occasion, CML may present as an isolated thrombocytosis. The diagnosis of CML may be confirmed with fluorescence in situ hybridization (FISH) or reverse transcriptase polymerase chain reaction (RT-PCR) for BCR-ABL performed on the peripheral blood. However, bone marrow aspiration with cytogenetic analysis (karyotype) is required to appropriately stage as the chronic phase, accelerated phase, or blast phase and to identify chromosomal abnormalities that are not detectable with FISH for BCR-ABL (Figures 3,4$).{ }^{12)}$

\section{TREATMENT}

TKI therapy has transformed the outcomes of patients with CML over the last 15 years. TKIs interfere with the interaction between the BCR-ABL oncoprotein and adenosine triphosphate, thereby blocking proliferation of the malignant clone. There are currently three TKIs approved by the Food and Drug Administration for the first-line treatment of chronic phase CML: imatinib, dasatinib, and nilotinib. Imatinib was the first TKI to be approved in 2001. In the landmark study comparing imatinib to combination interferon and cytarabine therapy, imatinib had superior tolerability, hematologic and cytogenetic responses, and decreased likelihood of progression to accelerated phase or blast phase CML. ${ }^{13)}$ The choice of first-line therapy depends on the Sokal or Hasford risk stratification score, patient age, ability to tolerate therapy, and medical comorbidities. The Sokal score includes age, spleen size, platelet count, and blast percentage. ${ }^{14)}$ The Hasford score also incorporates the percent of eosinophils and basophils. ${ }^{15)}$ Compared to imatinib,

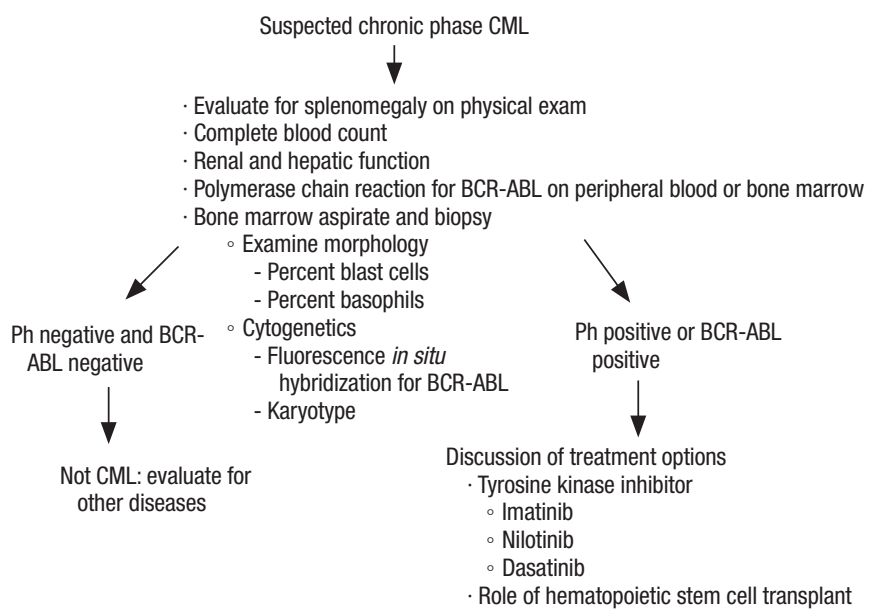

Figure 4. Evaluation of suspected CML. CML, chronic myeloid leukemia; BCR, breakpoint cluster region; $\mathrm{ABL}$, Abelson murine leukemia. 
dasatinib and nilotinib have improved efficacy and may be preferred in intermediate- and high-risk patients based on the Sokal or Hasford risk stratification scores. ${ }^{16-19)}$

In patients who are refractory or intolerant to first-line TKI therapy, second-line options include second-generation TKIs, dasatinib, nilotinib, and bosutinib. Ponatinib is a third-generation TKI and is the only TKI that is effective in patients who harbor the threonine-to-isoleucine mutation at position 315 (T315I). Previously, ponatinib was considered a third-line treatment option. However, due to the associated risk of arterial and venous thromboembolism, its use is generally reserved for patients harboring the T315I mutation. ${ }^{20,21)}$

All TKI agents are administered orally. The initial dosing and common and notable adverse effects are summarized in Table $2 .^{22,23)}$ The management of toxicities associated with TKI therapy is discussed elsewhere. ${ }^{12,24)}$ Patients with chronic phase CML are continued on TKI therapy indefinitely. Although discontinuation of TKI therapy with close molecular monitoring may be possible in selected patients, the discontinuation of TKI therapy should only been considered in the context of a clinical trial. ${ }^{12,25,26)}$

The response to therapy is classified based on hematological, cytogenetic, and molecular responses (Table 3). ${ }^{12)}$ Optimal responses to first-line TKI therapy include complete hematologic response with $B C R-A B L 1$ transcript $\leq 10 \%$ (RT-PCR) and/ or $\mathrm{Ph}$ positive cells $\leq 35 \%$ (bone marrow cytogenetics) at 3 months, $B C R-A B L 1$ transcript $<1 \%$ and/or no detectable $\mathrm{Ph}$ positive cells at 6 months, and $B C R-A B L 1$ transcript $\leq 0.1 \%$ at 12 months. Failure of first-line TKI therapy is defined as failure to achieve a complete hematologic response and/or $\mathrm{Ph}$ positive cells $>95 \%$ at 3 months, $B C R-A B L 1$ transcript $>10 \%$ and/or $\mathrm{Ph}$ positive cells $>35 \%$ at 6 months, and $B C R-A B L 1$ transcript $>1 \%$

Table 2. Tyrosine kinase inhibitors available for treatment of chronic phase chronic myeloid leukemia

\begin{tabular}{|c|c|c|c|c|c|}
\hline $\begin{array}{l}\text { Tyrosine kinase } \\
\text { inhibitors }\end{array}$ & $\begin{array}{l}\text { First-line } \\
\text { treatment }\end{array}$ & $\begin{array}{l}\text { Second-line } \\
\text { and } \\
\text { subsequent } \\
\text { therapy }\end{array}$ & Recommended dose & Common adverse effects ( $\geq 10 \%$ of patients) & Notable adverse events \\
\hline Imatinib (Gleevec) & Yes & No & $\begin{array}{l}400 \mathrm{mg} \text { orally once daily; } \\
\text { take with food }\end{array}$ & $\begin{array}{l}\text { Myelosuppression, fatigue, insomnia, depression, dizziness, } \\
\text { fluid retention, weight gain, upper respiratory tract infection, } \\
\text { influenza, pyrexia, cough, abdominal pain, nausea, vomiting, } \\
\text { diarrhea, myalgia, arthralgia, skin rash, hemorrhage }\end{array}$ & $\begin{array}{l}\text { Rarely associated with } \\
\text { appendiceal carcinoma }\end{array}$ \\
\hline Dasatinib (Sprycel) & Yes & Yes & $100 \mathrm{mg}$ orally once daily & $\begin{array}{l}\text { Myelosuppression, fatigue, fluid retention, headache, } \\
\text { dyspnea, infection, abdominal pain, nausea, diarrhea, } \\
\text { myalgia, arthralgia, skin rash, hemorrhage }\end{array}$ & Pleural effusion \\
\hline Nilotinib (Tasigna) & Yes & Yes & $\begin{array}{l}300 \text { mg orally twice daily } \\
\text { for first-line therapy, } 400 \\
\text { mg orally for refractory } \\
\text { disease; take on an empty } \\
\text { stomach }\end{array}$ & $\begin{array}{l}\text { Myelosuppression, fatigue, headache, nausea, vomiting, } \\
\text { diarrhea, constipation, skin rash, pruritis }\end{array}$ & QT interval prolongation \\
\hline Bosutinib (Bosulif) & No & Yes & $\begin{array}{l}500 \mathrm{mg} \text { once daily; take } \\
\text { with food }\end{array}$ & $\begin{array}{l}\text { Myelosuppression, fatigue, headache, dyspnea, cough, } \\
\text { pyrexia, abdominal pain, nausea, vomiting, diarrhea, } \\
\text { constipation, increased aspartate aminotransferase/ALT, } \\
\text { arthralgia, skin rash }\end{array}$ & \\
\hline Ponatinib (Iclusig) & No & $\begin{array}{l}\text { Yes; for the } \\
\text { patients with } \\
\text { the T315l } \\
\text { mutation }\end{array}$ & 45 mg once daily & $\begin{array}{l}\text { Myelosuppression, fatigue, headache, hypertension, } \\
\text { dyspnea, pyrexia, abdominal pain, pancreatitis, nausea, } \\
\text { constipation, increased ALT, myalgia, arthralgia, skin rash, } \\
\text { dry skin }\end{array}$ & $\begin{array}{l}\text { Arterial and venous } \\
\text { thrombosis } \\
\text { Hepatotoxicity, liver failure } \\
\text { and death }\end{array}$ \\
\hline
\end{tabular}

ALT, alanine aminotransferase.

Table 3. Assessment response to tyrosine kinase inhibitor therapy

\begin{tabular}{ll}
\hline & Content \\
\hline Complete hematologic response & Normalization of leukocyte count (white blood cell count $<10$ cells $\times 10^{9} / L$ ) and platelet count (platelets $<10$ cells $\left.\times 10^{9} / L\right)$, no immature \\
& cells or blasts in the peripheral blood, no signs or symptoms of disease with the disappearance of palpable splenomegaly \\
Cytogenetic response & $\%$ Philadelphia chromosome positive metaphases: (with a minimum of 20 metaphases examined) \\
& Minor: $35 \%-90 \%$ \\
& Partial: $1 \%-34 \%$ \\
& Major: $0 \%-35 \%$ (complete+partial) \\
Complete: $0 \%$ & Major: $\geq 3$ log reduction of BCR-ABL1 mRNA expression \\
Molecular response & Complete: $B C R$ - $A B L 1$ mRNA expression undetectable by reverse-transcriptase polymerase chain reaction \\
Relapse & Loss of hematologic or cytogenetic response
\end{tabular}

$\mathrm{BCR}$, breakpoint cluster region; $\mathrm{ABL}$, Abelson murine leukemia; mRNA, messenger ribonucleic acid. 
and/or Ph positive cells at 12 months. Loss of complete hematologic response, complete cytogenetic response, or major molecular response or presence of mutations or clonal evolution are also considered as treatment failure. ${ }^{8)}$

Administration of the protein synthesis inhibitor omacetaxine is a treatment option for patients who have failure or intolerance to two or more TKIs, including patients who harbor the T315I mutation. ${ }^{27,28)}$ The accelerated or blast phases may be treated with an alternative TKI as a bridge to HSCT. HSCT is a potentially curative treatment in patients with CML, and HSCT evaluation is recommended for patients with the T315I mutation, failure or intolerance to two or more TKIs, or those with accelerated or blast phase CML. ${ }^{12)}$

\section{PREGNANCY}

Although most pregnancy outcomes are normal in patients exposed to imatinib, there is still a risk for serious fetal malformation with imatinib exposure. ${ }^{29)}$ For this reason, discontinuation of TKI therapy is generally advised during pregnancy. ${ }^{12)}$ For women who desire pregnancy, a planned pregnancy is preferred. Once a woman is in at least a major molecular response, then a two to three month washout period of TKI therapy is advised prior to conception. TKI therapy should be held during pregnancy and resumed immediately after birth. When treatment is needed during pregnancy due to a very high white blood cell (WBC) count, leukapheresis is preferred..$^{30)}$ Interferon may be used safely in pregnancy. However, its use is limited by toxicity and slow time to response. ${ }^{31-33)}$ The use of hydroxyurea also appears to be safe in pregnancy, but its use is typically reserved for pulse dosing to control very high WBC counts. ${ }^{30,34-39)}$ Although the use of TKI appears to be safe in men fathering a child, patients should be advised that the data in this setting is limited. ${ }^{40-42)}$

\section{ROLE OF THE PRIMARY CARE PHYSICIAN}

Primary care physicians may be the first to detect CML since $40 \%$ patients present only with an abnormal blood count. ${ }^{6)}$ Thus, it is important for primary care physicians to be aware of the appropriate initial evaluation of patients with suspected CML.

During the routine follow-up of other medical comorbidities, the primary care physician may be the first to detect new adverse effects to TKI therapy, treatment failure, or progression of disease. With recognition of the common and serious adverse effects of TKI therapy, the primary care physician may provide appropriate counseling or arrange for earlier follow-up with the patient's hematologist/oncologist for management. With the recognition of possible treatment failure or progression of disease from the chronic phase to the accelerated or blast phases (i.e., increasing WBC count), the primary care physician should arrange for the patient to been seen by his/her hematologist/oncologist promptly for further evaluation.

\section{CONFLICT OF INTEREST}

No potential conflict of interest relevant to this article was reported.

\section{REFERENCES}

1. Siegel RL, Miller KD, Jemal A. Cancer statistics, 2015. CA Cancer J Clin 2015;65:5-29.

2. National Cancer Institute. SEER cancer statistics factsheets: chronic myeloid leukemia [Internet]. Bethesda (MD): National Cancer Institute; 2014 [cited 2015 Apr 20]. Available from: http://seer.cancer.gov/ statfacts/html/cmyl.html.

3. Kantarjian H, O’Brien S, Jabbour E, Garcia-Manero G, Quintas-Cardama A, Shan J, et al. Improved survival in chronic myeloid leukemia since the introduction of imatinib therapy: a single-institution historical experience. Blood 2012;119:1981-7.

4. Huang X, Cortes J, Kantarjian H. Estimations of the increasing prevalence and plateau prevalence of chronic myeloid leukemia in the era of tyrosine kinase inhibitor therapy. Cancer 2012;118:3123-7.

5. Rowley JD. Letter: a new consistent chromosomal abnormality in chronic myelogenous leukaemia identified by quinacrine fluorescence and Giemsa staining. Nature 1973;243:290-3.

6. Sawyers CL. Chronic myeloid leukemia. N Engl J Med 1999;340:133040.

7. Kantarjian HM, Keating MJ, Smith TL, Talpaz M, McCredie KB. Proposal for a simple synthesis prognostic staging system in chronic myelogenous leukemia. Am J Med 1990;88:1-8.

8. Baccarani M, Deininger MW, Rosti G, Hochhaus A, Soverini S, Apperley JF, et al. European LeukemiaNet recommendations for the management of chronic myeloid leukemia: 2013. Blood 2013 Aug 8;122: 872-84.

9. Swerdlow SH, Campo E, Harris NL, Jaffe ES, Pileri SA, Stein H, et al. World Health Organization classification of tumours of haematopoietic and lymphoid tissues. 4th ed. Lyon: International Agency for Research on Cancer Press; 2008.

10. Faderl S, Talpaz M, Estrov Z, O’Brien S, Kurzrock R, Kantarjian HM. The biology of chronic myeloid leukemia. N Engl J Med 1999;341:16472.

11. Savage DG, Szydlo RM, Goldman JM. Clinical features at diagnosis in 430 patients with chronic myeloid leukaemia seen at a referral centre over a 16-year period. Br J Haematol 1997;96:111-6.

12. O'Brien S, Radich JP, Abboud CN, Akhtari M, Altman JK, Berman E, et al. Chronic myelogenous leukemia, version 1.2015. J Natl Compr Canc Netw 2014;12:1590-610.

13. O'Brien SG, Guilhot F, Larson RA, Gathmann I, Baccarani M, Cervantes F, et al. Imatinib compared with interferon and low-dose cytarabine for newly diagnosed chronic-phase chronic myeloid leukemia. N Engl J Med 2003;348:994-1004.

14. Sokal JE, Cox EB, Baccarani M, Tura S, Gomez GA, Robertson JE, et al. Prognostic discrimination in "good-risk" chronic granulocytic leukemia. Blood 1984;63:789-99. 
15. Hasford J, Pfirrmann M, Hehlmann R, Allan NC, Baccarani M, KluinNelemans JC, et al. A new prognostic score for survival of patients with chronic myeloid leukemia treated with interferon alfa. Writing Committee for the Collaborative CML Prognostic Factors Project Group. J Natl Cancer Inst 1998;90:850-8.

16. Jabbour E, Kantarjian HM, Saglio G, Steegmann JL, Shah NP, Boque C, Chuah C, et al. Early response with dasatinib or imatinib in chronic myeloid leukemia: 3-year follow-up from a randomized phase 3 trial (DASISION). Blood 2014;123:494-500.

17. Kantarjian HM, Shah NP, Cortes JE, Baccarani M, Agarwal MB, Undurraga $\mathrm{MS}$, et al. Dasatinib or imatinib in newly diagnosed chronic-phase chronic myeloid leukemia: 2-year follow-up from a randomized phase 3 trial (DASISION). Blood 2012;119:1123-9.

18. Larson RA, Hochhaus A, Hughes TP, Clark RE, Etienne G, Kim DW, et al. Nilotinib vs imatinib in patients with newly diagnosed Philadelphia chromosome-positive chronic myeloid leukemia in chronic phase: ENESTnd 3-year follow-up. Leukemia 2012;26:2197-203.

19. Larson RA, Kim DW, Jootar S, Pasquini R, Clark RE, Lobo C, et al. ENESTnd 5-year (y) update: long-term outcomes of patients (pts) with chronic myeloid leukemia in chronic phase (CML-CP) treated with frontline nilotinib (NIL) versus imatinib (IM). J Clin Oncol 2014;32(15_ suppl):7073.

20. Cortes JE, Kim DW, Pinilla-Ibarz J, le Coutre P, Paquette R, Chuah C, et al. A phase 2 trial of ponatinib in Philadelphia chromosome-positive leukemias. N Engl J Med 2013;369:1783-96.

21. Food and Drug Administration. FDA drug safety communication: FDA investigating leukemia drug Iclusig (ponatinib) after increased reports of serious blood clots in arteries and veins. Silver Spring (MD): Food and Drug Administration; 2013.

22. Hochhaus A, O'Brien SG, Guilhot F, Druker BJ, Branford S, Foroni L, et al. Six-year follow-up of patients receiving imatinib for the first-line treatment of chronic myeloid leukemia. Leukemia 2009;23:1054-61.

23. ARIAD Pharmaceuticals Inc. Ponatinib [Internet]. Cambridge (MA): ARIAD Pharmaceuticals Inc.; 2012 [cited 2015 Apr 25]. Available from: http://www.accessdata.fda.gov/drugsatfda_docs/label/2012/203469lbl. pdf.

24. Akhtari M, Barber NA. Practical approach to the hematologic adverse effects of imatinib. In: Akhtari M, El-Helmaidi I, editors. Imatinib: chemical structure, pharmacology and adverse effects. Hauppauge (NY): Nova Science Publishers Inc.; 2013. p. 65-80.

25. Mahon FX, Rea D, Guilhot J, Guilhot F, Huguet F, Nicolini F, et al. Discontinuation of imatinib in patients with chronic myeloid leukaemia who have maintained complete molecular remission for at least 2 years: the prospective, multicentre Stop Imatinib (STIM) trial. Lancet Oncol 2010;11:1029-35.

26. Ross DM, Branford S, Seymour JF, Schwarer AP, Arthur C, Bartley PA, et al. Patients with chronic myeloid leukemia who maintain a complete molecular response after stopping imatinib treatment have evidence of persistent leukemia by DNA PCR. Leukemia 2010;24:1719-24.

27. Cortes JE, Nicolini FE, Wetzler M, Lipton JH, Akard L, Craig A, et al. Subcutaneous omacetaxine mepesuccinate in patients with chronic-phase chronic myeloid leukemia previously treated with 2 or more tyrosine kinase inhibitors including imatinib. Clin Lymphoma Myeloma Leuk 2013;13:584-91.

28. Cortes J, Lipton JH, Rea D, Digumarti R, Chuah C, Nanda N, et al. Phase 2 study of subcutaneous omacetaxine mepesuccinate after TKI failure in patients with chronic-phase CML with T315I mutation. Blood 2012; 120:2573-80.

29. Pye SM, Cortes J, Ault P, Hatfield A, Kantarjian H, Pilot R, et al. The effects of imatinib on pregnancy outcome. Blood 2008;111:5505-8.

30. Cortes J, Kantarjian H. How I treat newly diagnosed chronic phase CML. Blood 2012;120:1390-7.

31. El-Hemaidi I, Robinson SE. Management of haematological malignancy in pregnancy. Best Pract Res Clin Obstet Gynaecol 2012;26:149-60.

32. Baer MR, Ozer H, Foon KA. Interferon-alpha therapy during pregnancy in chronic myelogenous leukaemia and hairy cell leukaemia. Br J Haematol 1992;81:167-9.

33. Kuroiwa M, Gondo H, Ashida K, Kamimura T, Miyamoto T, Niho Y, et al. Interferon-alpha therapy for chronic myelogenous leukemia during pregnancy. Am J Hematol 1998;59:101-2.

34. Delmer A, Rio B, Bauduer F, Ajchenbaum F, Marie JP, Zittoun R. Pregnancy during myelosuppressive treatment for chronic myelogenous leukemia. Br J Haematol 1992;82:783-4.

35. Patel M, Dukes IA, Hull JC. Use of hydroxyurea in chronic myeloid leukemia during pregnancy: a case report. Am J Obstet Gynecol 1991;165: 565-6.

36. Tertian G, Tchernia G, Papiernik E, Elefant E. Hydroxyurea and pregnancy. Am J Obstet Gynecol 1992;166(6 Pt 1):1868.

37. Jackson N, Shukri A, Ali K. Hydroxyurea treatment for chronic myeloid leukaemia during pregnancy. Br J Haematol 1993;85:203-4.

38. Baykal C, Zengin N, Coskun F, Guler N, Ayhan A. Use of hydroxyurea and alpha-interferon in chronic myeloid leukemia during pregnancy: a case report. Eur J Gynaecol Oncol 2000;21:89-90.

39. Celiloglu M, Altunyurt S, Undar B. Hydroxyurea treatment for chronic myeloid leukemia during pregnancy. Acta Obstet Gynecol Scand 2000; 79:803-4.

40. Ault P, Kantarjian H, O'Brien S, Faderl S, Beran M, Rios MB, et al. Pregnancy among patients with chronic myeloid leukemia treated with imatinib. J Clin Oncol 2006;24:1204-8.

41. Ramasamy K, Hayden J, Lim Z, Mufti GJ, Ho AY. Successful pregnancies involving men with chronic myeloid leukaemia on imatinib therapy. Br J Haematol 2007; 137:374-5.

42. Cortes J, O'Brien S, Ault P, Borthakur G, Jabbour E, Bradley-Garelik B, et al. Pregnancy outcomes among patients with chronic myeloid leukemia treated with dasatinib. Blood 2008;112:Abstract 3230. 